\title{
Garenoxacin Prophylaxis for Febrile Neutropenia after Chemotherapy in Hematological Malignancies
}

\section{Nobuhiko Nakamura, Takeshi Hara, Soranobu Ninomiya, Yuhei Shibata, Takuro Matsumoto, Hiroshi Nakamura, Junichi Kitagawa, Yasuhito Nannya, Masahito Shimizu, Nobuo Murakami, Hisashi Tsurumi}

Department of Hematology, Gifu University Graduate School of Medicine, Gifu, Japan

Email: htsuru@gifu-u.ac.jp

How to cite this paper: Nakamura, N., Hara, T., Ninomiya, S., Shibata, Y., Matsumoto, T., Nakamura, H., Kitagawa, J., Nannya, Y., Shimizu, M., Murakami, N. and Tsurumi, H. (2016) Garenoxacin Prophylaxis for Febrile Neutropenia after Chemotherapy in Hematological Malignancies. Open Journai of Internal Medicine, 6, 128-138. http://dx.doi.org/10.4236/ojim.2016.64018

Received: October 7, 2016

Accepted: December 3, 2016

Published: December 6, 2016

Copyright $\odot 2016$ by authors and Scientific Research Publishing Inc. This work is licensed under the Creative Commons Attribution International License (CC BY 4.0).

http://creativecommons.org/licenses/by/4.0/

\section{Abstract}

Background: Febrile neutropenia is one of the most serious adverse events in patients with hematological malignancies and chemotherapy. The routine use of fluoroquinolone prophylaxis in patients with hematological malignancies is controversial. Therefore, we prospectively evaluated the efficacy and safety of prophylactic use of garenoxacin for febrile neutropenia. Patients and Methods: Consecutive adult patients with hematological malignancies who were at risk for chemotherapy-induced neutropenia lasting more than seven days were eligible for present study. They received oral garenoxacin (400 $\mathrm{mg}$ daily) from the neutrophil count decreased to less than $1000 / \mu l$ and continued until the neutropenia had resolved. The primary endpoint was incidence of febrile neutropenia, and the secondary endpoints were the type and incidence of adverse events. Results: We enrolled 46 consecutive patients (median age, 59 years). The underlying diseases comprised acute myeloid leukemia $(\mathrm{n}=17)$, acute lymphoblastic leukemia $(\mathrm{n}=3)$, malignant lymphoma $(\mathrm{n}$ =23), and multiple myeloma $(n=3)$. There were 23 febrile neutropenia episodes and 2 episodes of bacteremia. There were no grade 3 or 4 adverse events; however serum creatinine levels were significantly elevated after garenoxacin administration. The overall prophylactic efficacy of garenoxacin was $50 \%$, and there were no infection-related deaths. Conclusions: Prophylactic use of garenoxacin is effective and safe in patients with hematological malignancies. (Clinical trial registration number: UMIN000004979).

\section{Keywords}

Febrile Neutropenia, Prophylaxis, Garenoxacin, Hematological Malignancies 


\section{Introduction}

Febrile neutropenia (FN) is a significant cause of mortality in patients who develop severe neutropenia after chemotherapy in hematological malignancies [1]. It has been reported that prophylactic use of antibiotics, particularly fluoroquinolones, reduces the prevalence of febrile neutropenia, bacteremia, and even infection-related mortality [2] [3] [4]. According to the guidelines of the Infectious Diseases Society of America, quinolones such as ciprofloxacin and levofloxacin are recommended for prophylactic use. Indeed, levofloxacin is the most preferred quinolone because of its activity against gram-positive bacteria [5]. However, the emergence of bacterial resistance to antibiotics has become a concern and routine prophylactic use remains controversial [6] [7].

Garenoxacin mesylate hydrate (GRNX) is a novel oral des-fluoro(6) quinolone with potent antimicrobial activity, including antibiotic-resistant strains [8]. GRNX acts on DNA gyrase and topoisomerase IV to inhibit the transcription and replication of DNA as with other fluoroquinolones [9]. GRNX showed marked antimicrobial activity against a broad spectrum of organisms, including gram-positive and gram-negative bacteria. However, to our knowledge, the prophylactic use of GRNX has not been reported. Hence, we prospectively examined the efficacy and safety of prophylactic use of GRNX in patients with hematological malignancies.

\section{Patients and Methods}

\subsection{Patients}

Adult patients ( $\geq 16$ years of age) with hematological malignancies who were hospitalized at Gifu University Hospital and who were at risk for chemotherapy-induced neutropenia (absolute neutrophil count $<1000 / \mu \mathrm{l}$ ) lasting for more than 7 days were eligible for the present study [10]. All patients could be enrolled for only one chemotherapy cycle. The exclusion criteria were as follows: known uncontrolled bacterial infection at the time of enrollment; serum levels of aspartate aminotransferase (AST) or alanine aminotransferase (ALT) $>10$-fold the upper limit of normal; serum total bilirubin levels of $>3 \mathrm{mg} / \mathrm{dl}$; serum creatinine levels of more than two fold the upper limit of normal; a history of anaphylaxis reactions to fluoroquinolones; HIV seropositivity; or pregnancy.

\subsection{Study Design}

This prospective study was conducted between March 2011 and November 2013 at Gifu University Hospital, and the Institutional Review Board approved the study protocol. Written informed consent was obtained from each patient before enrollment in the study. This trial is registered with the University Hospital Medicine Information Network (UMIN) (Clinical Trials Registry, No. UMIN000004979). The primary end point of the study was the incidence of FN. Secondary end points were the type and number of documented infections, survival at the resolution of neutropenia, and adverse events.

\subsection{Treatment}

Oral GRNX (400 mg daily) was started after the neutrophil count decreased to less than 
$1000 / \mu \mathrm{l}$ and continued until the neutropenia had resolved (more than $1000 / \mu \mathrm{l})$. All patients were examined daily for clinical signs of infection. When axillary temperature exceeded $37.5^{\circ} \mathrm{C}$ and an infection was suspected, samples were obtained for microbiologic cultures, including at least two separate blood specimens, and empirical antibacterial therapy was started. Concurrent prophylactic use of trimethoprim/sulfamethoxazole against Pneumocystis jirovecii, antifungal prophylaxis and/or oral acyclovir against herpes viruses were allowed. The administration of granulocyte-colony stimulating factors for neutropenia was also allowed. Isolated bacteria were identified with the use of standard methods, and susceptibility was examined [11].

\subsection{Definitions}

Fever in neutropenic patients was defined as a single axillary temperature of $>37.5^{\circ} \mathrm{C}$. The definition of neutropenia was an absolute neutrophil count (ANC) $<1500 / \mu l$. Severe neutropenia was defined as an ANC $<500 / \mu$ or that was expected to decrease below 500/ $\mu$ l during the next 48 hours, and profound neutropenia was an ANC $<100 / \mu \mathrm{l}$ [5]. The risk classification of FN was defined according to the Multinational Association for Supportive Care in Cancer risk (MASCC) index [12]. Adverse events were graded according to the National Cancer Institute Common Toxicity Criteria version 3.0, and the maximum grade during the administration of GRNX was recorded. Differences between the results of comparative tests were considered statistically significant if $\mathrm{P}<0.05$. All statistical analyses were performed with EZR version 1.26 software [13].

\section{Results}

\subsection{Patients}

We enrolled 46 patients (median age, 59 years; range, 17 - 81 years, 26 men and 20 women). Table 1 summarizes the clinical characteristics of the patients at study entry. Underlying diseases consisted of acute myeloid leukemia (AML) $(n=17)$, acute lymphoblastic leukemia (ALL) $(n=3)$, multiple myeloma $(M M)(n=3)$, and malignant lymphoma $(M L)(n=23)$. Most AML patients underwent standard intensive chemotherapy, consisting of cytosine arabinoside (Ara-C) and anthracycline [14]. In brief, induction therapy consisted of $12 \mathrm{mg} / \mathrm{m}^{2}$ of idarubicin (IDA) on days $1-3$ and 100 $\mathrm{mg} / \mathrm{m}^{2}$ of Ara-C on days $1-7$ or $50 \mathrm{mg} / \mathrm{m}^{2}$ of daunorubicin on days $1-5$ and 100 $\mathrm{mg} / \mathrm{m}^{2}$ of Ara-C on days $1-7$. Consolidation chemotherapy for patients with core binding factor -AML was comprised of high-dose Ara-C, and the other AML patients underwent three or four courses of standard consolidation chemotherapy based on Ara-C and anthracyclines. Most ML patients underwent the R-CHOP (rituximab, cyclophosphamide, doxorubicin, vincristine, prednisone) or R-THP-COP (rituximab, cyclophosphamide, tetrahydropyranyl-adriamycin, vincristine, prednisone) regimen [15] [16]. One case of AML and one case of ALL received allogeneic hematopoietic stem cell transplantation (HSCT). All cases of MM received high-dose chemotherapy followed by autologous HSCT. The median duration of administration of GRNX was 9.5 days 
Table 1. Patient characteristics.

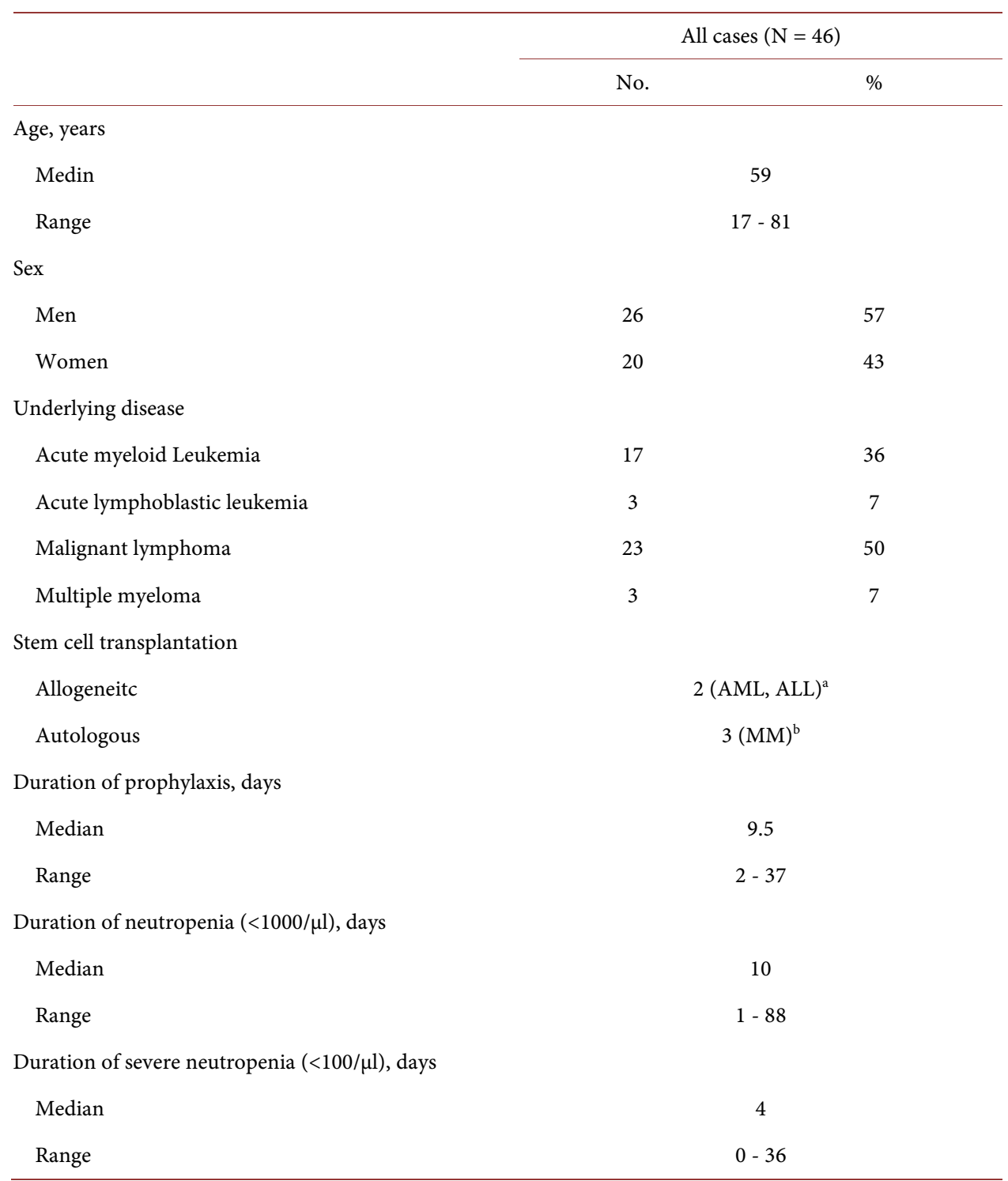

a. AML: Acute myeloid leukemia; ALL: Acute lymphoblastic leukemia; b. MM: Multiple myeloma.

(range, 2 - 37 days). The median duration of neutropenia $(<1000 / \mu \mathrm{l})$ was 10 days (range, 1 - 88 days), and the median duration of severe neutropenia $(<100 / \mu \mathrm{l})$ was 4 days (range, 0 - 36 days). The risk classification according to the MASCC index is shown in Table 2.

\subsection{Febrile Neutropenia}

Table 3 shows the incidence of FN, 23 developed FN of 46 patients (50\%). There were no significant differences between groups in age or sex. However, patients with AML or MM had a significantly higher incidence of FN than patients with ALL or ML (76\% and $100 \%$ versus $33 \%$ and $26 \%$, respectively, $\mathrm{P}=0.0018$ ). All patients who received autologous or allogeneic HSCT developed FN, and patients who did not receive autologous 
Table 2. MASCC score.

\begin{tabular}{lccc}
\hline \multirow{2}{*}{ Characteristics } & \multicolumn{3}{c}{$\mathrm{FN}^{\mathrm{a}}$ episodes $(\mathrm{N}=23)$} \\
\cline { 2 - 4 } Burden of illness & Score & No. & \\
No or mild symptoms & 5 & 21 & $91 \%$ \\
Moderate symptoms & 3 & 2 & $9 \%$ \\
No hypotension & 5 & 22 & $96 \%$ \\
No chronic obstructive pulmonary disease & 4 & 23 & $100 \%$ \\
Solid tumor or no previous fungal infection & 4 & 23 & $100 \%$ \\
No dehydration & 3 & 23 & $100 \%$ \\
Outpatient status & 3 & 0 & $0 \%$ \\
Age $<60$ years & 2 & 11 & $48 \%$ \\
High risk (Score $\leq 20)$ & & 1 & $4 \%$ \\
\hline
\end{tabular}

${ }^{\mathrm{a}} \mathrm{FN}$ : Febrile neutropenia.

Table 3. Febrile episodes.

\begin{tabular}{|c|c|c|c|c|c|}
\hline & \multicolumn{2}{|c|}{ Total patients } & \multicolumn{2}{|c|}{$\mathrm{FN}^{\mathrm{a}}$ episodes } & \multirow[b]{2}{*}{ P-value } \\
\hline & No. & $\%$ & No. & No. & \\
\hline All cases & 46 & & 23 & 50 & \\
\hline \multicolumn{6}{|l|}{ Age } \\
\hline$<60 \mathrm{yr}$ & 23 & 50 & 12 & 52 & N.S. ${ }^{b}$ \\
\hline$\geq 60 \mathrm{yr}$ & 23 & 50 & 11 & 48 & \\
\hline \multicolumn{6}{|l|}{ Sex } \\
\hline Men & 26 & 57 & 14 & 54 & N.S. ${ }^{b}$ \\
\hline Women & 20 & 43 & 9 & 45 & \\
\hline \multicolumn{6}{|l|}{ Underlying disease } \\
\hline Acute myeloid leukemia & 17 & 36 & 13 & 76 & 0.0018 \\
\hline Acute lymphoblastic leukemia & 3 & 7 & 1 & 33 & \\
\hline Malignant lymphoma & 23 & 50 & 6 & 26 & \\
\hline Multiple myeloma & 3 & 7 & 3 & 100 & \\
\hline \multicolumn{6}{|l|}{ Stem-cell transplantation } \\
\hline With & 5 & 11 & 5 & 100 & 0.006 \\
\hline Without & 41 & 89 & 18 & 44 & \\
\hline \multicolumn{6}{|l|}{ Intravenous catheter in situ } \\
\hline With & 32 & 70 & 20 & 63 & 0.0003 \\
\hline Without & 14 & 30 & 3 & 21 & \\
\hline \multicolumn{6}{|l|}{$\begin{array}{l}\text { Duration of neutropenia } \\
(<1000 / \mu \mathrm{l})\end{array}$} \\
\hline$<7$ days & 14 & 30 & 3 & 21 & 0.0087 \\
\hline$\geq 7$ days & 32 & 70 & 20 & 63 & \\
\hline \multicolumn{6}{|l|}{$\begin{array}{l}\text { Duration of severe neutropenia } \\
(<100 / \mu \mathrm{l})\end{array}$} \\
\hline$<7$ days & 31 & 67 & 10 & 32 & 0.0003 \\
\hline$\geq 7$ days & 15 & 33 & 13 & 87 & \\
\hline
\end{tabular}

${ }^{\mathrm{a}} \mathrm{FN}$ : Febrile neutropenia, ${ }^{\mathrm{b}}$ N.S.: not significant. 
or allogeneic HSCT had a significantly lower incidence of FN than that of patients who received autologous or allogeneic HSCT ( $44 \%$ versus $100 \%$, respectively, $\mathrm{P}=0.006$ ). $\mathrm{Pa}$ tients with an intravenous catheter had a significantly higher incidence of FN as compared with patients without an intravenous catheter (63\% versus $21 \%$, respectively, $\mathrm{P}=$ 0.0003). Patients with duration of neutropenia $(<1000 / \mu l)$ or severe neutropenia $(<100 / \mu l)$ more than 7 days had a significantly higher incidence of FN than that less than 7 days ( $63 \%$ versus $21 \%, \mathrm{P}=0.0087,87 \%$ versus $32 \%, \mathrm{P}=0.0003$, respectively).

\subsection{Infections}

Two sets of blood cultures from a peripheral vein and any indwelling venous catheters were taken from all FN patients. Two cases of bacteremia (one each of Methicillinresistant Staphylococcus epidermidis (MRSE) and Campylobacter upsaliensis) were observed. Campylobacter upsaliensis was resistant to fluoroquinolone (minimum inhibitory concentration $\geq 32 \mu \mathrm{g} / \mathrm{mL}$ ). The positive rate of blood culture was $8.7 \%$. All FN patients were treated with empirical antibacterial therapy, and there were no infectionrelated deaths.

\subsection{Adverse Events}

Adverse events were observed in 17 patients (37\%). Fourteen patients developed grade 1 or 2 liver dysfunction, and 3 patients experienced grade 1 renal dysfunction. There were no grade 3 or 4 adverse events, and compliance of GRNX was good. We compared serum AST, ALT, creatinine and eGFR before and after administration of GRNX (Figure 1). There were no significant differences between before and after administration of GRNX in serum AST or ALT ( $\mathrm{P}=0.0637, \mathrm{P}=0.4119$, respectively). In contrast, serum creatinine levels were significantly elevated and eGFR was significantly reduced after administration of GRNX $(P=0.0018)$.

\section{Discussion}

Bacterial infections are still a major cause of morbidity and mortality in patients with neutropenia following chemotherapy in hematological malignancies [17]. Bucaneve et al. reported the efficacy of levofloxacin prophylaxis in reducing the incidence of bacterial infections in patients with cancer and neutropenia [2]. The Australian Consensus Guidelines conclude that the evidence is not sufficient to recommend prophylactic use of antibiotics [18]. In contrast, in other guidelines, such as the IDSA [5], ESMO [19], ASCO [20], and NCCN [21], prophylactic use of fluoroquinolone was recommended for high-risk patients who are going to be neutropenia for more than 7 days. Levofloxacin may be most used as a prophylactic antibiotic for FN in patients with hematological malignancies in the world. Uni et al. retrospectively compared the prophylactic use of GRNX with LVFX in AML [22], and reported that there was no significant difference in FN events in the two groups ( $86 \%$ of the GRNX group and 78\% of the LVFX group). In the present study, we prospectively examined the safety and efficacy of GRNX as a prophylactic antibiotic for the patients with hematological malignancies and showed 


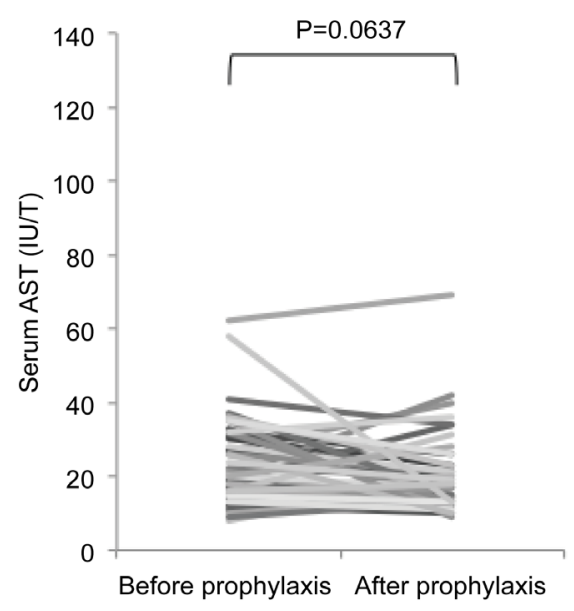

(a)

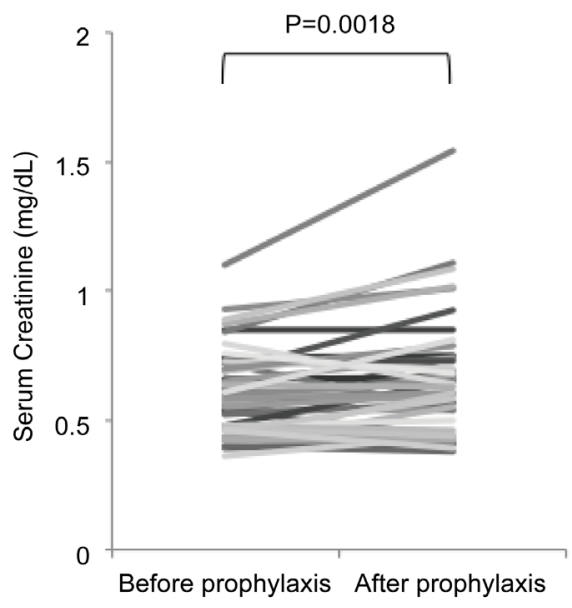

(c)

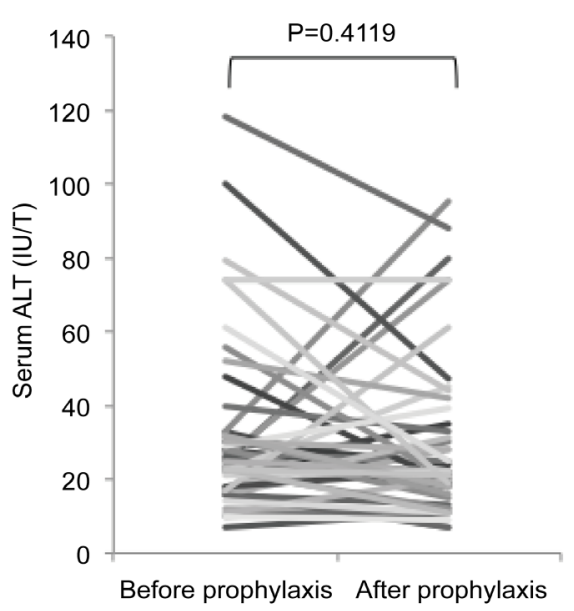

(b)

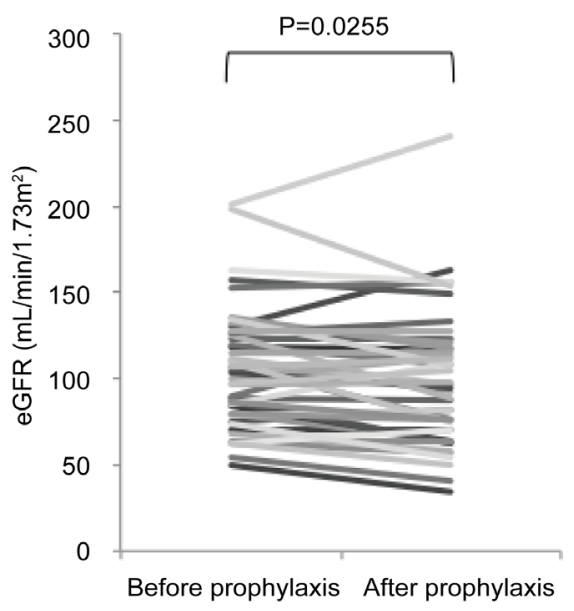

(d)

Figure 1. (a) Serum levels of AST; (b) Serum levels of ALT; (c) Serum levels of creatinine; and (d) eGFR before and after GRNX prophylaxis.

that the efficacy of the GRNX prophylaxis for 32 patients that had more than 7 days of neutropenia (neutrophil count $<1000 / \mu \mathrm{L}$ ) was $37 \%$. We recognized that the prophylactic use of GRNX was sufficient to prevent FN as compared to LVFX in previous studies [22].

In the present study, AML or MM patients had a significantly higher incidence of FN than ALL or ML patients. In addition, patients who received HSCT had a significantly higher incidence of FN than the patients who did not receive HSCT. Patients with duration of neutropenia more than 7 days had a significantly higher incidence of FN. We estimated that a long period of myelosuppression was most important risk factor for FN. Hence, these high-risk patients might be good targets for the prophylactic use of GRNX, as a result, we could not find a sufficient prophylactic effect of GRNX.

Fluoroquinolones are widely used for the prevention and management of infections in patients with neutropenia, however, there are important concerns about the emergence of fluoroquinolone-resistant bacteria [23]. Indeed, one case of fluoroquinolone- 
resistant bacteria confirmed by blood culture was observed in the present study, Campylobacter upsaliensis. Fluoroquinolone resistance may be associated with community fluoroquinolone consumption, and the prophylaxis effect may be reduced if the prevalence of gram-negative bacillary resistance to fluoroquinolone develops more than $20 \%$ [24]. The emergence of methicillin-resistant Staphylococcus aureus might be associated with prophylactic use of fluoroquinolone [24] [25]. In contrast, there were two cohort studies that showed quinolone prophylaxis did not affect the emergence of fluoroquinolone-resistant gram-negative isolates in patients with FN. Fluoroquinolone resistance may not be induced by the use of quinolone alone [26] [27]. However, a meta-analysis showed that prophylactic use of fluoroquinolone was associated with high rate of resistance [28]. The emergence of resistant bacteria should be continuously monitored.

It was known that there were some problems with the safety of fluoroquinolones such as renal dysfunction, liver dysfunction, QTc prolongation, abnormal glucose tolerance, photosensitivity, arthropathy and central nervous system disturbance [29] [30]. Pre-clinical examinations of GRNX showed that GRNX had a sufficient safety [31] [32]. In the present study, although grade 1 or 2 liver dysfunction was observed in 4 cases (5.9\%), there were no serious adverse events. Hence, we considered that GRNX had sufficient safety to be used for prophylaxis of FN in patients with hematological malignancies. Most fluoroquinolones including LVFX are excreted mainly by the renal route. In contrast, GRNX is well-balanced excretion by both the renal and fecal route [33]. LVFX is metabolized in the kidney, but GRNX is metabolized in both the liver and kidney. This difference in excretion route may be very important for prophylactic use in patients with renal dysfunction. Although we routinely cannot use LVFX in patients with renal dysfunction, GRNX could be used in these patients. However, serum creatinine levels were significantly elevated and eGFR was significantly reduced after administration of GRNX in the present study. Of course, we could not exclude the influence of the chemotherapy for the underlying disease. Anyway, we must carefully monitor serum creatinine levels in patients who receive administration of GRNX.

Our study showed enough efficacy and safety of GRNX for prophylactic use after chemotherapy in hematological malignancies. However, the number of this study sample was small, and our present study was designed as single arm study, not randomized, hence, our study had the limitation. It might be worth to conduct further clinical study of GRNX, such as the randomized phase III study compared with LVFX.

\section{Conclusion}

Prophylactic use of GRNX is effective and safe in patients with hematological malignancies. The emergence of quinolone-resistant bacteria was observed. Hence, periodic surveillance is very important to detect the emergence of resistant bacteria by prophylactic use of GRNX.

\section{Acknowledgements}

We thank Miho Yagi, Chiyoko Sano, Hitomi Fujisawa, and Eriko Kunishima for their 
secretarial and technical assistance.

\section{References}

[1] Viscoli, C. and Castagnola, E. (2002) Treatment of Febrile Neutropenia: What Is New? Current Opinion in Infectious Diseases, 15, 377-382.

https://doi.org/10.1097/00001432-200208000-00004

[2] Bucaneve, G., Micozzi, A., Menichetti, F., Martino, P., Dionisi, M.S., Martinelli, G., et al. (2005) Levofloxacin to Prevent Bacterial Infection in Patients with Cancer and Neutropenia. New England Journal of Medicine, 353, 977-987. https://doi.org/10.1056/NEJMoa044097

[3] Gafter-Gvili, A., Fraser, A., Paul, M. and Leibovici, L. (2005) Meta-Analysis: Antibiotic Prophylaxis Reduces Mortality in Neutropenic Patients. Annals of Internal Medicine, 142, 979-995. https://doi.org/10.7326/0003-4819-142-12_Part_1-200506210-00008

[4] Leibovici, L., Paul, M., Cullen, M., Bucaneve, G., Gafter-Gvili, A., Fraser, A., et al. (2006) Antibiotic Prophylaxis in Neutropenic Patients: New Evidence, Practical Decisions. Cancer, 107, 1743-1751. https://doi.org/10.1002/cncr.22205

[5] Freifeld, A.G., Bow, E.J., Sepkowitz, K.A., Boeckh, M.J., Ito, J.I., Mullen, C.A., et al. (2011) Clinical Practice Guideline for the Use of Antimicrobial Agents in Neutropenic Patients with Cancer: 2010 Update by the Infectious Diseases Society of America. Clinical Infectious Diseases, 52, e56-e93. https://doi.org/10.1093/cid/cir073

[6] Pascoe, J. and Steven, N. (2009) Antibiotics for the Prevention of Febrile Neutropenia. Current Opinion in Hematology, 16, 48-52. https://doi.org/10.1097/MOH.0b013e32831ac543

[7] Cullen, M. and Baijal, S. (2009) Prevention of Febrile Neutropenia: Use of Prophylactic Antibiotics. British Journal of Cancer, 101, S11-S14. https://doi.org/10.1038/sj.bjc.6605270

[8] Takagi, H., Tanaka, K., Tsuda, H. and Kobayashi, H. (2008) Clinical Studies of Garenoxacin. International Journal of Antimicrobial Agents, 32, 468-474. https://doi.org/10.1016/j.ijantimicag.2008.06.032

[9] Takahata, M., Mitsuyama, J., Yamashiro, Y., Yonezawa, M., Araki, H., Todo, Y., et al. (1999) In Vitro and in Vivo Antimicrobial Activities of T-3811ME, a Novel Des-F(6)-Quinolone. Antimicrobial Agents and Chemotherapy, 43, 1077-1084.

[10] Hughes, W.T., Armstrong, D., Bodey, G.P., Feld, R., Mandell, G.L., Meyers, J.D., et al. (1990) From the Infectious Diseases Society of America. Guidelines for the Use of Antimicrobial Agents in Neutropenic Patients with Unexplained Fever. Journal of Infectious Diseases, 161, 381-396. https://doi.org/10.1093/infdis/161.3.381

[11] Geddes, A., Thaler, M., Schonwald, S., Harkonen, M., Jacobs, F. and Nowotny, I. (1999) Levofloxacin in the Empirical Treatment of Patients with Suspected Bacteraemia/Sepsis: Comparison with Imipenem/Cilastatin in an Open, Randomized Trial. Journal of Antimicrobial Chemotherapy, 44, 799-810. https://doi.org/10.1093/jac/44.6.799

[12] Klastersky, J., Paesmans, M., Rubenstein, E.B., Boyer, M., Elting, L., Feld, R., et al. (2000) The Multinational Association for Supportive Care in Cancer Risk Index: A Multinational Scoring System for Identifying Low-Risk Febrile Neutropenic Cancer Patients. Journal of Clinical Oncology, 18, 3038-3051.

[13] Kanda, Y. (2013) Investigation of the Freely Available Easy-to-Use Software "EZR" for Medical Statistics. Bone Marrow Transplantation, 48, 452-458. https://doi.org/10.1038/bmt.2012.244

[14] Miyazaki, Y., Kuriyama, K., Miyawaki, S., Ohtake, S., Sakamaki, H., Matsuo, T., et al. (2003) Cytogenetic Heterogeneity of Acute Myeloid Leukaemia (AML) with Trilineage Dysplasia: 
Japan Adult Leukaemia Study Group-AML 92 Study. British Journal of Haematology, 120, 56-62. https://doi.org/10.1046/j.1365-2141.2003.03981.x

[15] Hara, T., Tsurumi, H., Goto, N., Kitagawa, J., Kanemura, N., Yoshikawa, T., et al. (2010) Phase II Study of Rituximab Combined with THP-COP as First-Line Therapy for Patients Younger than 70 Years with Diffuse Large B Cell Lymphoma. Journal of Cancer Research and Clinical Oncology, 136, 65-70. https://doi.org/10.1007/s00432-009-0637-x

[16] Kasahara, S., Hara, T., Tsurumi, H., Goto, N., Kitagawa, J., Kanemura, N., et al. (2011) Phase II Study of the Tetrahydropyranyl Adriamycin-Cyclophosphamide, Vincristine, and Prednisolone Regimen Combined with Rituximab as First-Line Treatment for Elderly Patients with Diffuse Large B-Cell Lymphoma. Leukemia and Lymphoma, 52, 629-634. https://doi.org/10.3109/10428194.2011.555024

[17] Bow, E.J. (2005) Management of the Febrile Neutropenic Cancer Patient: Lessons from 40 Years of Study. Clinical Microbiology and Infection, 11, 24-29.

https://doi.org/10.1111/j.1469-0691.2005.01240.x

[18] Slavin, M.A., Lingaratnam, S., Mileshkin, L., Booth, D.L., Cain, M.J., Ritchie, D.S., et al. (2011) Use of Antibacterial Prophylaxis for Patients with Neutropenia. Australian Consensus Guidelines 2011 Steering Committee. Internal Medicine Journal, 41, 102-109. https://doi.org/10.1111/j.1445-5994.2010.02341.x

[19] De Naurois, J., Novitzky-Basso, I., Gill, M.J., Marti, F.M., Cullen, M.H., Roila, F., et al. (2010) Management of Febrile Neutropenia: ESMO Clinical Practice Guidelines. Annals of Oncology, 21, v252-v256. https://doi.org/10.1093/annonc/mdq196

[20] Flowers, C.R., Seidenfeld, J., Bow, E.J., Karten, C., Gleason, C., Hawley, D.K., et al. (2013) Antimicrobial Prophylaxis and Outpatient Management of Fever and Neutropenia in Adults Treated for Malignancy: American Society of Clinical Oncology Clinical Practice Guideline. Journal of Clinical Oncology, 31, 794-810. https://doi.org/10.1200/JCO.2012.45.8661

[21] Baden, L.R., Bensinger, W., Angarone, M., Casper, C., Dubberke, E.R., Freifeld, A.G., et al. (2012) Prevention and Treatment of Cancer-Related Infections. Journal of the National Comprehensive Cancer Network, 10, 1412-1445.

[22] Uni, M., Yoshimi, A., Yamazaki, S., Taoka, K., Shinohara, A., Nannya, Y., et al. (2015) Comparison of Garenoxacin with Levofloxacin as Antimicrobial Prophylaxis in Acute Myeloid Leukemia. Japanese Journal of Clinical Oncology, 45, 745-748. https://doi.org/10.1093/jjco/hyv071

[23] De Rosa, F.G., Motta, I., Audisio, E., Frairia, C., Busca, A., Di Perri, G., et al. (2013) Epidemiology of Bloodstream Infections in Patients with Acute Myeloid Leukemia Undergoing Levofloxacin Prophylaxis. BMC Infectious Diseases, 13, 563. https://doi.org/10.1186/1471-2334-13-563

[24] Bow, E.J. (2011) Fluoroquinolones, Antimicrobial Resistance and Neutropenic Cancer Patients. Current Opinion in Infectious Diseases, 24, 545-553. https://doi.org/10.1097/QCO.0b013e32834cf054

[25] Kjellander, C., Bjorkholm, M., Cherif, H., Kalin, M. and Giske, C.G. (2012) Hematological: Low All-Cause Mortality and Low Occurrence of Antimicrobial Resistance in Hematological Patients with Bacteremia Receiving No Antibacterial Prophylaxis: A Single-Center Study. European Journal of Haematology, 88, 422-430. https://doi.org/10.1111/j.1600-0609.2012.01768.x

[26] Chong, Y., Yakushiji, H., Ito, Y. and Kamimura, T. (2011) Clinical Impact of Fluoroquinolone Prophylaxis in Neutropenic Patients with Hematological Malignancies. International Journal of Infectious Diseases, 15, e277-281. https://doi.org/10.1016/j.ijid.2010.12.010 
[27] Trecarichi, E.M. and Tumbarello, M. (2014) Antimicrobial-Resistant Gram-Negative Bacteria in Febrile Neutropenic Patients with Cancer: Current Epidemiology and Clinical Impact. Current Opinion in Infectious Diseases, 27, 200-210. https://doi.org/10.1097/QCO.0000000000000038

[28] Gafter-Gvili, A., Paul, M., Fraser, A. and Leibovici, L. (2007) Effect of Quinolone Prophylaxis in Afebrile Neutropenic Patients on Microbial Resistance: Systematic Review and Meta-Analysis. Journal of Antimicrobial Chemotherapy, 59, 5-22. https://doi.org/10.1093/jac/dkl425

[29] Stahlmann, R. (2002) Clinical Toxicological Aspects of Fluoroquinolones. Toxicology Letters, 127, 269-277. https://doi.org/10.1016/S0378-4274(01)00509-4

[30] Ball, P. (2003) Adverse Drug Reactions: Implications for the Development of Fluoroquinolones. Journal of Antimicrobial Chemotherapy, 51, 21-27. https://doi.org/10.1093/jac/dkg209

[31] Nagai, A., Miyazaki, M., Morita, T., Furubo, S., Kizawa, K., Fukumoto, H., et al. (2002) Comparative Articular Toxicity of Garenoxacin, a Novel Quinolone Antimicrobial Agent, in Juvenile Beagle Dogs. Journal of Toxicological Sciences, 27, 219-228. https://doi.org/10.2131/jts.27.219

[32] Nakamura, T., Fukuda, H., Morita, Y., Soumi, K. and Kawamura, Y. (2003) Pharmacological Evaluation of Garenoxacin, a Novel Des-F(6)-Quinolone Antimicrobial Agent: Effects on the Central Nervous System. Journal of Toxicological Sciences, 28, 35-45. https://doi.org/10.2131/jts.28.35

[33] Villafuerte-Gutierrez, P., Villalon, L., Losa, J.E. and Henriquez-Camacho, C. (2014) Treatment of Febrile Neutropenia and Prophylaxis in Hematologic Malignancies: A Critical Review and Update. Advances in Hematology, 2014, Article ID: 986938. https://doi.org/10.1155/2014/986938

\section{Submit or recommend next manuscript to SCIRP and we will provide best service for you:}

Accepting pre-submission inquiries through Email, Facebook, LinkedIn, Twitter, etc. A wide selection of journals (inclusive of 9 subjects, more than 200 journals)

Providing 24-hour high-quality service

User-friendly online submission system

Fair and swift peer-review system

Efficient typesetting and proofreading procedure

Display of the result of downloads and visits, as well as the number of cited articles

Maximum dissemination of your research work

Submit your manuscript at: http://papersubmission.scirp.org/

Or contact ojim@scirp.org 